\title{
Capital-centric versus knowledge-centric paradigms of human resource management: A historical perspective
}

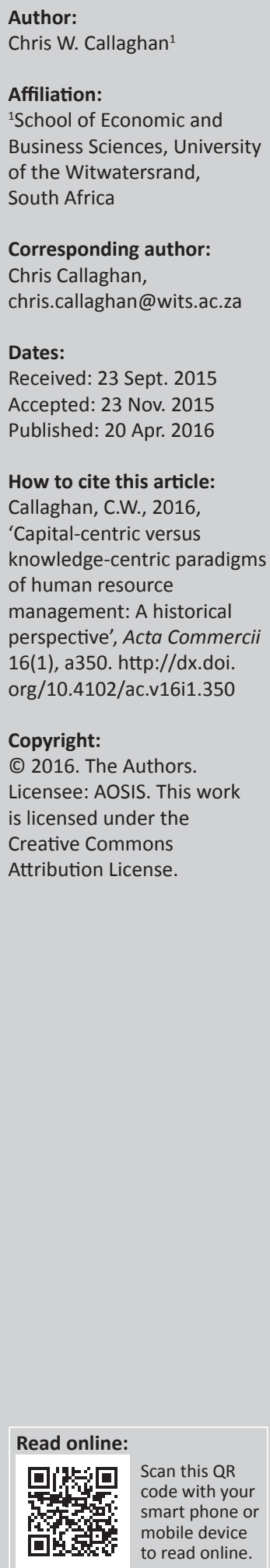

Orientation: Central to understanding the contemporary state of the human resource management (HRM) field is knowledge of its history, and the underlying rationales as to why it has changed over time. This research attempts to identify one such important 'rationale'.

Research purpose: This article relates certain changes in HRM over time to the argument that there has been a shift from an industrial paradigm (on which many human resource [HR] systems, practices and theoretical frameworks are still based) to a knowledge paradigm (of knowledge work, in which employee knowledge and skills offer compound advantages that are not substitutable) which explains a great deal of the variance in changes of the field over time.

Motivation for the study: It is argued that in order for the field to move forward, it may need to bring to the surface certain assumptions and differentiate between theoretical frameworks when dealing with knowledge work versus non-knowledge work.

Research design, approach and method: This article offers a perspective of HR theory development over time. It is a conceptual/perspectives article and is not qualitative nor quantitative in nature. Further research will be able to test the ideas presented here.

Practical/managerial implications: Managers and human resources managers need to differentiate between knowledge and non-knowledge work. The latter is associated with increased heterogeneity and complexity, and differences in power relationships, as knowledge work shifts power away from capital into the hands of skilled knowledge labour.

\section{Introduction}

At the heart of changes in the academic and practitioner fields of human resource management (HRM) are the influences of broader changes in the literature underlying HRM thought. This article argues that certain paradigmatic changes in the world of work are not fully recognised for their impact on HRM, or for their impact on other fields, and that the failure to recognise the implications of these changes imposes serious costs on HRM as an academic discipline.

Further, this article contests that although the global rates of return on capital have been found to exceed the rate of growth and outcome over certain periods of history (Piketty 2014:20), another effect has had a greater influence within the field of HRM over the past centuries, namely the shift in power relationships away from 'capital' and toward 'knowledge', as potential returns to knowledge have come to greatly exceed returns to capital in a globalised economy (Callaghan 2012:5), dramatically increasing the historical importance of HRM over time in relation to other organisational functions.

Where many theories birthed in economics suggest that historical changes in HRM over time derive from capital-centric relationships (related to the returns to financial capital as a dominant factor of production), it is argued here that HRM theory itself offers core insights into wealth creation based on knowledge-centric relationships (and returns to knowledge as a dominant factor of production) which are increasingly salient in the contemporary globalised knowledge economy; and which apply to individuals or firms, in that the human individual is inseparable from valuable endowments of tacit knowledge (Nonaka 1994:15; Polanyi 1973:16), a source of heterogeneous competitive advantage for firms in the 'knowledge economy' (Organisation of Economic Co-operation and Development [OECD] 1996). 
This article therefore seeks to provide an outline of certain changes in the HRM field over time, building on the work of others (such as Stone \& Deadrick 2014:139) in arguing that an era of capital-centric theory has waned and that the effects of the information revolution, and the knowledge economy it has spawned, are no less pervasive than the consequences of the industrial revolution of more than a century past. Arguably, if not differentiated as to their different predictions for HRM practice, theory suited differently to each of these two eras if applied to the incorrect type of work perpetuates the potential for ideological confounds and constraints to the development of the field.

For Piketty (2014) a 'root cause' of human inequality is to be found in the way capitalism generates arbitrary and unsustainable inequalities in societies, because of the way capital acts and its returns in societies:

Modern economic growth and the diffusion of knowledge have made it possible to avoid the Marxist apocalypse but have not modified the deep structures of capital and inequality - or in any case not as much as one might have imagined in the optimistic decades following World War II. When the rate of return on capital exceeds the rate of growth of output and income, as it did in the nineteenth century and seems quite likely to do again in the twenty first, capitalism automatically generates arbitrary and unsustainable inequalities that radically underline the meritocratic values on which democratic societies are based. There are nevertheless ways democracy can regain control over capitalism and ensures that the general interest takes precedence over private interests, while preserving economic openness and avoiding protectionist and nationalist reactions. (p. 1)

For HRM, the notion of inequalities in earnings is not unfamiliar territory. For Mincer the (1958) 'root cause' of inequality is also recognised as a seminal paradox in scientific thought, explained as follows:

Since income inequality is observable in terms of the shape or parameters of statistical frequency distributions, theories of the determinants of personal income distribution, if they are to be operational, must predict features of the observable statistical constructs. Probably the oldest theory of this type is the one that relates the distribution of income to the distribution of individual abilities. A special form of this theory can be attributed to Galton, who claimed that 'natural abilities' follow the Gaussian normal law of error...A seemingly natural corollary of this logic was the hypothesis of a normal distribution of incomes.... [yet] the hypothesis of a normal distribution of incomes was definitively shattered by Pareto's famous 'law' of incomes. For a long time this refutation of a logically weak hypothesis was considered to represent a strange puzzle. Pigou termed it a paradox. How can one reconcile the normal distribution of abilities with a sharply skewed distribution of incomes? This became the central question around which thinking on the subject subsequently revolved. (pp. 281-282)

Mincer (1958:282), however, in his seminal work differs in what is considered a candidate for the role of 'root cause' of inequality in earnings, and whilst not discounting the role of capital, offers the basis for an alternative perspective of the 'root cause' of income inequality in societies:
One answer, of comparatively recent origin, is that the abilities relevant to earning power should not be identified with intelligence quotients (IQ.'s). Indeed, relevant abilities are likely not to be normally distributed, as IQ's are, but to be distributed in a way resembling the distribution of income. This amounts to saying that income distributions should not be deduced from psychological data on distributions of abilities, but, conversely, that the latter, which are not observable, should be inferred from the former.

Having contested an important assumption at the time, Mincer (1958:282) derives a model of investments that relate to a different form of capital, namely human capital, associated with knowledge and training, which can also account for the skewed distribution of earnings typically associated with inequality. The seminal tension between Mincer's (1958:282) and Piketty's (2014:14) perspectives can perhaps be taken to boil down to a tension between the prediction that differences in capital are the primary 'root cause' of inequality in earnings in societies, versus the prediction that differences in human capital (knowledge investments in individuals) are the primary 'root cause' of inequality in earnings in societies. This article argues that the former argument is fundamentally related to a paradigm that is no longer dominant in 'knowledge' work; and that there are serious consequences that accrue to HRM as a field, and to societies in general, if knowledge of the full implications of this paradigm shift is not explicitly acknowledged.

It is argued that the skew between rich and poor, and between less successful organisations and those more successful, might increase dramatically in future, and not primarily as a result of differences in capital, but because of the exponential returns to knowledge (ideas and innovations) that accrue to nations, organisations and individuals under certain conditions. Therefore the plight of nations, organisations and individuals facing a context of increasing inequality in incomes as a result of the power of knowledge highlights the importance of fields such as HRM which are uniquely placed to offer useful insight into the way knowledge can be leveraged to provide national, organisational and individual competitive advantage.

This article proceeds as follows. Firstly, the divergence of HRM theory and practice is considered, in order to ground the arguments made in this paper in relation to the broader context of change within the field. Next, the notion of two revolutions in work processes that relate to two productivity enhancing paradigms is explored in order to set the stage for a discussion of the historical development of HRM as a field of practice as well as a field of study. The dichotomy between HRM practice and research is then introduced as a key theme in the discussion, and literature relating to changes in HRM over time is then reviewed in relation to certain arguments. Finally, the contemporary era of HRM is discussed, and it is argued that a lack of paradigmatic differentiation continues to prevail in contemporary HRM. 


\section{Divergence of human resource management theory and practice}

The shift from manufacturing to a services or knowledgebased economy has had fundamental implications for HR, as many traditional HR processes have their genesis in the industrial era and were developed to support manufacturing organisations. Contemporary $\mathrm{HR}$ is still saddled with problematic assumptions and processes, such as notions of narrow job definitions, control of workers, efficiency and a focus on short term results (Stone \& Deadrick 2014:140).

In contrast, the knowledge economy has a different dynamic, and it is employees' knowledge and skills (which are not homogenous but defy substitution) that are at the heart of organisational success. These jobs need to be designed to emphasise autonomy and participation in decision-making, use team oriented structures to enhance collaboration and innovation, stress training and employee skill development, and provide incentives that foster employee identification, innovation and retention (Stone \& Deadrick 2014:140).

The focus of this article is the development of the field of HRM over time, and what makes a discussion of Piketty's (2014) work relevant here is the lack of transformation of HR theory, practice (Stone \& Deadrick 2014:139) and ideology (Callaghan 2012:6) in knowledge work, away from a focus on capital, or industrial/manufacturing-centric HR systems and practices, to a knowledge-economy focus, given the exponentially higher returns on knowledge than what can accrue to capital (OECD 1996). The consequences that currently accrue to the field of HRM from a failure to successfully shift from a primary or secondary sector-related 'capital' focus to a services or knowledge sector-related 'knowledge of employees' focus are especially salient in an era of rapid globalisation (Stone \& Deadrick 2014), and many of the contemporary definitional problems associated with HRM are taken here to exist as a consequence of this tension.

Organisations operating in globalised environments also face relatively new challenges, such as language and cultural differences, as well as differences in social, political and legal systems, which in turn have implications for HR practices (Stone \& Deadrick 2014:139). It is argued here that until the core 'DNA' of the HRM field has been identified (and its 'genome' sequenced so that theorists and practitioners understand the confounds inherent in its lack of appropriate transformations in its theory and practices from industrial era to knowledge era processes), attempts by the field to develop will be held back by inconsistencies embedded in processes and assumptions at the core of the field. Through a consideration of the changes in HRM over time, this article seeks to contribute to this process.

According to the literature, some have suggested that talent management (the identification of HR needs and the planning undertaken to meet them) and technology (information technology applied to store and communicate HR data) are the two primary contemporary drivers of change in HR (Stone \& Deadrick 2014:139). It is argued that the returns to human knowledge that can be leveraged through the judicious application of talent management processes and information technology can result in returns to organisations that can exceed the returns to capital in general. It is also argued that HRM as a field needs to explicitly differentiate itself according to the HR requirements associated with the two different paradigms of work discussed above. Failure to do so may perpetuate process confounds in the field, and perpetuate the emergence of subordinate fields of HRM, such as 'talent management', or the management of 'human capital', which at their heart might simply be streams of HRM literature that are responsive of the need of organisations for the exponential returns to knowledge that HR theory and practice is uniquely placed to support.

\section{Historical development of human resource management}

In order to trace the development of HRM as a field, it is necessary to identify the contestations and trends within its literature. This, necessarily, requires any contemporary arguments to be placed in relation to the evolution of the field over time. A key argument of this article is that the failure to differentiate between two incommensurate paradigms in HRM is evidenced in certain confounds reflected in a current lack of definitional clarity that surrounds the field and 'what it does'. This lack of clarity might, however, be accounted for using a temporal framework; the implication, then, is that these different definitions reflect different stages of the field's development path, reflecting fundamentally incommensurate HRM paradigms. Certain definitional and other problems associated with contemporary HRM are now considered, prior to the discussion of the historical development of HRM which is taken into account for the presence of certain of these contemporary problems faced by the field.

\section{Definitional contestation in contemporary human resource management}

Kaufman (2014:213) highlights the presence of a '... number of distinct and partially incommensurate definitions of HRM' in the contemporary literature and argues that after '... a century of development, the concept of HRM still does not have a consistent definition' as twenty-five years '... after the HRM concept was popularised multiple definitions flourish'.

The literature offers ample examples of how the management field as well as the HRM field are '... subject to recurrent fads and a penchant for writers to reinvent the wheel' which is reflected in the use of the concepts of HRM strategy, horizontal and vertical fit, the resource based view of the firm and the commitment model in the literature a century ago (Kaufman 2014). The HRM field has therefore suffered from a lack of integration, according to Kaufman (2014), who explains this problem further as follows: 
From the beginning of personnel and industrial relations in the early 1920s, however, the study of HRM has tended to fracture along several fault lines which divide the field into disciplinary / subject silos. One fault line centres on unions and, more generally, the need for curbs on management power and parallel protection for employees. Another divider is level of analysis, ranging from individual cognitions on the micro end to national unemployment on the macro end. Yet a third is the split between internalist and externalist perspectives. The divide in the study of HRM is anchored on the internalist side by psychology and on the externalist side by economics. Currently, the externalist and internalist wings of HRM are much like two long-separated wings of a family ... unable to communicate to each other because they speak different languages and have different cultural traditions. (p. 214)

It is argued here that at the heart of this divergence has been the emergence of the role of power associated with knowledge in human work. Whereas power relationships associated with industrialisation, and manufacturing in particular placed dominance squarely in the hands of the owners of capital, the emergence of the knowledge worker became associated with a more complex interplay of power relationships, under which capital lost much of its power relative to knowledge. And in interaction effects with capital, knowledge increasingly provided the more dynamic contribution to outcomes.

It is argued here that divergence between 'capital-centric' and 'knowledge-centric' working contexts can be taken to reflect differences between returns to capital and returns to knowledge. These differences, in turn, can be taken to reflect the divergence between HRM research and practice. Ironically, where the gap between capital-rich and capitalpoor produced severe inequality effects in the industrial era, the gap between knowledge-rich and knowledge-poor in the knowledge era has the potential to create much higher differentials of inequality. Organisations that better capture and leverage the knowledge (ideas and innovativeness) of their employees can better differentiate themselves in terms of competitive advantage than those that used capital as their differentiator in the previous era. What has changed, however, is the fact that knowledge can be developed by those without it with much more ease than capital can. A failure to differentiate between these paradigms might, however, lead to a disjointed relationship between research and practice. In the sections which follow, certain arguments are considered in relation to different aspects of the historical development of HRM, including the relationships between HRM research and practice over time.

\section{Human resource management practice versus research}

DeNisi, Wilson and Jiang (2014:222) argue that the '... struggle by Business School faculty to be taken as serious academicians' has led to 'reward systems' that incentivise theory-based rather than problem-solving papers, a trend related to the historical development of the HRM field. In terms of criticisms that HR managers do not typically follow the academic literature, another reason for this offered by the literature is 'mimetic isomorphism', or the tendency for firms to seek legitimacy through benchmarking the practices of other firms, and their reluctance to choose evidence-based research over the legitimacy associated with sticking to widely 'legitimised' best practices; which essentially represent not much more than managerial fads and fashions, or 'bandwagon effects' that consequently stifle innovation (DeNisi et al. 2014:219).

The current state of HRM is thus to some extent dictated by historical trends in the field. With regard to another fundamental tension between different 'camps', namely strategic human resource management (SHRM) and industrial relations (IR), Kaufman (2014) offers the following summary of the current state of the field:

To some degree SHRM and IR serve as bridges between disciplines and externalist vs. internalist perspectives; however, these bridges appear to be relatively thin and sporadically crossed. Just as a historical review of HRM suggests that research and teaching in, say, the 1920s, 1950s, or 1980s would have been strengthened by greater contact, integration and ecumenical spirit across disciplines, such is surely the case today. Unfortunately, history also teaches that getting researchers to talk to each accordingacross these dividing lines (or to talk across the academic-practitioner boundary) is difficult to initiate and sustain, particularly as publish or perish pressures ratchet upward. (p. 214)

Again, the argument is posed that differences between externalist and internalist perspectives, and indeed the differentiation between SHRM and IR, to some extent reduce to fundamental differences in work tasks and the nature of work between 'industrial' work and knowledge work.

HRM systems derive their logic from systems theory; these systems need to be practically useful, and typically contribute to the management of innovation and environmental stability (Jackson, Schuler \& Jiang 2014). Systems theory might have the potential to incorporate diverse aspects of HRM, and thereby include both industrial and knowledge aspects of the field within its theoretical framework. Systems theory also offers a framework within which to explore the relationships between HRM practices and performance as a dimension of SHRM. However, the potential of SHRM theory to deliver on its promise has also been questioned. It is possible that this failure could be the result of the incorporation of both industrial, or capital-centric work and knowledge-centric work within overarching work systems.

Jackson et al. (2014:2) argue that the '... broad aspirations apparent in the field's [SHRM] early seminal works have yet to be realised as the seeds of important conceptual ideas have been neglected, perhaps because rigorous empirical tests of the field's complex core concepts have proved extremely difficult to conduct'. At the heart of these difficulties is perhaps the intangible nature of knowledge, and the lack of an explicit framework that seeks to thread out the HRM contribution to performance when differentiated by returns to capital and returns to knowledge, and, indeed, the exact nature of the contributions of their interactions. 
Wright and Haggerty (2005:171) called on the field to develop comprehensive theories that integrate relationships across levels of analysis or which '... link organisational concepts to individual concepts back to other organisational concepts', stressing that '... theories and research on issues such as schemas/cognitive processes, social information processing, individual differences, and motivational theories can provide valuable explanation to the individual processes that are being triggered by organisational level HRM practices'. A process of mapping knowledge relationships within the organisation and linking these directly with performance and quantifying the intra-organisational returns to knowledge builds on Wright and Haggerty's (2005) notion of developing comprehensive theories that integrate relationships across levels of analysis. At this point, the historical context of the development of the field is discussed in relation to the arguments made in this article.

\section{The capital paradigm: the industrial revolution versus the post-capital paradigm and the dominance of knowledge over capital}

The first recorded modern instance of an organisation creating a dedicated HRM unit was the case of the National Cash Register Company in the US, which after labour problems organised a personnel department to handle worker's grievances; threats of unionisation as well as the need to increase record keeping capacity spurred other firms to follow suit (DeNisi et al. 2014:219). Labour and HRM problems, according to Kaufman (2014:199), are timeless, as problems with motivation, turnover and skills deficits persist, which are typically dealt with on the one hand by a '... low road commodity/autocracy/adversarial approach and on the other by a high road human capital/participative/ cooperative approach', or combinations between. Arguably, the former approach is associated with the industrial paradigm and the latter with the knowledge paradigm; it is argued here that certain characteristics of the former are incommensurate with the latter.

In about 1910, the employment management movement emerged, which, following the crisis of World War I, split into two streams, namely personnel management and IR (Kaufman 2014). This was perhaps the first attempt by the field to (perhaps correctly) deal with the potential confounds between industrial-type work and knowledge-type work.

IR differed from personnel management in that it was more strategic, liberal, social-minded, externally oriented, and encompassed the entire employment relationship; but its intellectual base was in institutional labour economics, which also drew from sociology, management and law (Kaufman 2014:200). In contrast to the IR stream, personnel management developed a closer relationship with management objectives, and was more managerialist and internally focused, drawing its intellectual guidance from individualist theory and micro behavioural disciplines such as industrial psychology, which were by nature less strategically focused than IR (Kaufman 2014:200). It is argued here that the alignment of theory with the objectives of management (a different perspective from the IR field), reflects a fundamentally different dynamic, in that the emergence of knowledge workers (and labour heterogeneity) led to an approach to theory and practice that is incommensurate with the adversarial nature of IR theory and practice. Knowledge workers, with the potential to develop a local monopoly in knowledge that is tacit (Von Hippel 1994; Nonaka 1994) and inseparable from the individual (Polanyi 1973, are not powerless in the face of capital, and the returns on their knowledge can, if leveraged, exceed the returns to capital. Arguably, at the core of this differentiation are the power differences between knowledge and capital, which gave rise to the tension between the internalist and externalist orientations of academic HRM.

\section{Differentiations within the field}

According to Kaufman (2014:201), this phase of the development of HRM can be described as a differentiation between the externalist orientation of IR, grounded in economics, and the internalist orientation of personnel management, grounded in psychology. HRM's development in the 1920s gave rise to widespread concerns, as autocratic styles predominated in some industries whilst in others a cooperative and human capital type of HRM emerged, particularly in welfare capitalist companies, and two academic centres developed for HRM teaching, namely economics departments (IR) and business schools (personnel management), the latter with a more vocational focus, albeit with less prestige than their economic counterparts (Kaufman 2014:210).

Although conflict between these economics departments and business schools developed, these differences were overshadowed by the advent of the great depression in the 1930s, which, despite the best intentions of companies, led to a reversal of trust as lay-offs and an intense focus on costs became a necessity for survival, and the labour problem re-emerged as a dominant problem in HRM as unitarism was discredited and pluralism emerged as the new paradigm (Kaufman 2014:206). Arguably, the effect of the great depression was to shift the power balance away from knowledge toward capital, as the supply of labour and knowledge resources dominated the supply-demand equation.

From the depression, another movement emerged with roots in industrial sociology and industrial-organisational psychology, namely the human relations movement which stood in contrast to the emergence of management as a discipline at the time, which drew from economics and industrial engineering, on the basis of how it conceptualised human work. Human relations regarded human labour as much more important (and complex) than the reductionist model, or the narrow perspective of early management theorists, who regarded human labour as primarily a function of rational or mechanistic choices based on incentives (Kaufman 2014:204). These changes may reflect the strengthening role of psychology, a discipline perhaps uniquely matched to the heterogeneity of labour and the importance of individual differences, given the inseparability 
of scarce and tacit knowledge from the individual, as stressed by Polanyi's (1973) seminal work.

\section{The human relations era and the knowledge revolution}

The Hawthorne Studies (1927-1935) gave rise to the human relations era, which was premised on the notion that employee attitudes are fundamentally related to employee productivity, and personnel departments were tasked with 'keeping their employees happy' with the understanding that happier workers are likely to not only be more productive but also less likely to join unions (DeNisi et al. 2014:220). What is not recognised in this account by DeNisi et al. (2014:220), however, are the emerging tensions between the capital and post-capital paradigms, as under the industrial paradigm of Fordism, work could be specialised and workers were interchangeable, and their homogeneity offered no protection from industrialists; keeping them happy was therefore simply less of an imperative under the capital paradigm.

Human relations as a field offered a behavioural-social model of human labour, and posited the existence of a social system in the workplace, over and above the technical/economic system, which was critically important in order to elicit effective cooperation. From this perspective, labour problems:

$[R]$ eflect social maladjustments inside organisations that produce conflict and inhibit teamwork; management, accordingly, has the ability to solve labour problems through HRM practices that meet workers' psycho-social needs, collaborate with rather than undercut informal work groups, and promote a humanistic leadership style- all of which engender an alignment of interests, more effective cooperation, and high organisational performance. (Kaufman 2014:205)

What seems clear from this interpretation is the intensification of commitment on the part of organisations to the needs of workers.

Over this period, personnel management and human relations were faced with certain challenges relating to ideological perceptions that they were 'tools of management' focused on increasing worker satisfaction in order to improve management performance, and as tools of union avoidance (Kaufman 2014:206). It is argued here that this ideological perception has been the cause of confounds in the development of HRM theory and practice, because the notion of power in capital-dominant contexts can become conflated with the power relationships associated with knowledgedominant work. Marxist doctrine is perhaps a better 'fit' with capital-dominant, or primary/secondary work in which labour is relatively more homogenous and powerless, but less so in contexts where an individual can take a course of study and develop scarce knowledge skills, and effectively change 'class' in a relatively short period of time. Arguably, the knowledge economy, with its high returns to scare skills and knowledge, places the individual in a different power dynamic relative to capital.
Personnel management's (PM's) reputation faced challenges not only in the working realm, but its academic reputation suffered as it was located in vocationally oriented business schools, and was regarded as lacking in intellectual content as a descriptive and technique-oriented subject. Economics $\mathrm{PhDs}$ faced reputational risk when choosing to teach PM in business schools at the time (Kaufman 2014:205). From the late 1950s industrial relations (IR) and PM had started to differentiate themselves from each other, and the behaviourist, or micro-focussed approach of PM competed with the macro, or analytical, focus of traditional IR-related HRM (Kaufman 2014:205). The rivalry between these two schools came to a head in the late 1950s over the human relations school, along the micro versus macro dimension (Kaufman 2014:205). But there were also other forces at play, one of which was the way business schools sought to relate to their practitioner fields in terms of the dichotomy between research and teaching.

\section{Role of the academy}

In 1959, according to DeNisi et al. (2014:221), a turning point was reached in the way HRM was taught and researched in business schools on the basis of two reports, by Gordon and Howell (1959:1) and Pierson (1959), which criticised business schools for the lack of rigour in their offerings, and for an excessive focus on consulting and case study teaching, as well as a lack of theory and theory development, particularly in terms of integrating work from the liberal arts disciplines and their theoretical frameworks. The use of case studies and the use of consulting work to write papers was, however, precisely the reason for the close alignment of HR research with HR practice until this time. Nevertheless, business schools sought to increase their academic credibility and undertook to increase their focus on basic and theoretical research, and more staff were hired from the liberal arts disciplines to do this; and central to this process was the hiring of staff from the psychological and economics disciplines (DeNisi et al. 2014:221).

This led to a trend of divergence between HR research and practice, and this impact was to be felt more strongly over time (DeNisi et al. 2014:221). At the heart of this divergence might also be the fundamental disconnect between theory from the liberal arts disciplines at the time (1959 to 1980), which included a focus on the work of capital-centric theorists such as Marx and others whose work developed on the back of the industrial revolution as well as in response to the plight of workers who were relatively powerless under the industrial, or capital-centric paradigm. It is argued that little in the liberal arts ambit of theory at the time contested this body of theory strongly enough to be considered by HR managers to be useful in their management of newly emerged knowledge workers. Arguably, this disconnect reflects the groundswell of the effects of the information revolution, and the rise of the knowledge worker associated with this revolution; and the emergence of the knowledge paradigm and the inversion of power relationships in these contexts. However, in the absence of an inversion of the assumptions of dominant ideologies, the field was perhaps left with little 
choice but to distance itself from IR as an academic field associated with a capital-centric ideology, notwithstanding the prestige associated with these other fields at the time.

However, by the late 1970s IR had gravitated toward a less multidisciplinary focus on its institutional tradition, and pluralism, unions, collective bargaining and labour policy, and PM remained managerial-focused with an administrative/ psychological perspective to employment issues, offering the view that unions can pose a serious constraint to workplace cooperation and performance, notwithstanding their existential necessity (Kaufman 2014:200). The development of PM in this period seems to reflect the tensions between capitalcentric theory and its assumptions of labour powerlessness and homogeneity (as well as its hostility to management), and the development of knowledge-centric theory associated with PM as it sought to understand knowledge workers and their labour heterogeneity (and, hence, the increasing complexity of knowledge work), and the relatively more equal power relationships between capital and knowledge workers. It is clear, however, from an analysis of this period that the thrust of the information revolution was still to work its way through the workplace context, particularly the influences of the advent of the personal computer and the electronic productivity tools of the information revolution which were to accelerate the rise of knowledge-centric theory.

At the time (late 1970s), PM distanced itself from IR, building on its location in business schools, and its usefulness in business contexts, allying with the administrative and behavioural sciences and supplanting the traditional academic focus on conflict and power inequalities with a new focus on cooperation and goal alignment (Kaufman 2014:200). Arguably, the grand narrative provided by capital-centric theory such as Marxism is less helpful in the new information revolution context of knowledge work, and PM was to morph into a field of study more supportive of attempts to harness knowledge in the form of human beings as the primary asset of organisations. The returns to individual labour therefore became increasingly important and created a context in which bivariate analysis (two factors - homogenous labour and capital) was no longer capable of capturing the nuances of complex returns to knowledge, particularly those which in turn accrued to multiple sets of stakeholders, and which were increasingly difficult to measure using the statistical measures of applied economics.

At this time the PM field distanced itself further from the anti-managerial ideology associated with the liberal arts focus on conflict and power and its adversarial ideology, and instead sought what was to become a more 'value adding' approach based on the alignment of stakeholder interests, with the HR division of the academy of management as its centre; a field differing fundamentally from IR according to its internalist, micro, behaviourist and individualist approaches (Kaufman 2014:207). For Kaufman (2014:207), when the 'divorce happened, IR walked away feeling it had not lost much', as PM '... in industry was for the most part on the lowest rung of the managerial ladder; in the academic world no professor achieved a "big name" by specialising in personnel and few found intellectual stimulation' in the mundane techniques of PM. However, it is argued that this 'divorce' heralded a wave that was building, and that was about to break in the form of the information revolution, as the post-capital paradigm of knowledge work and the rise of the knowledge worker.

\section{Information technology productivity revolution}

Stone et al. (2014:216) stress that information technology systems typically face certain fundamental challenges in their support of HR processes. Notwithstanding these challenges, technology has transformed HR practice, both in terms of information use as well as the nature of jobs and work itself, as productivity enhancements have allowed returns to knowledge to be more effectively and efficiently captured. Arguably, the advent of the information revolution, and the influence of its dramatic productivity enhancements, began to be felt most acutely from the 1980s onwards. It is argued that the split between the industrial relations research stream and the PM/Organisational Behaviour (OB) stream reflects the dramatic productivity enhancements of this information, or knowledge 'revolution', which made a focus on the psychological aspects of human resources (HR) key to the retention and management of people, who were increasingly becoming the primary (albeit heterogeneous and complex) knowledge assets contributing to competitive advantage. Arguably, whereas under the industrial paradigm workers were perhaps alienated from their work product, the knowledge worker was able to regain autonomy and control over his or her work, and was once more the craftsman/ craftswoman in knowledge work. Thus, Marx's vision, as it relates to the alienation of labour, is, ironically, reconciled with the processes of knowledge work, and the re-engagement of the worker with intrinsic rewards of work.

The field of IR split from PM/OB in the 1960s and 1970s, focusing instead on union-management relations. However, union density dropped dramatically and in the 1980s the IR field realigned itself to focus on behavioural aspects and the new 'high performance' paradigm, taking a strategic perspective, and developed a stream of literature concerned with employment systems (Kaufman 2014). These changes seem to reflect the shift toward harnessing of returns to knowledge and information which was increasingly sought by firms over this period, and a shift towards a knowledgebased, or services-centric economy.

\section{Human resource management at the nexus of subordinate fields}

Despite advantages derived from its external focus which were well suited to strategic issues of HRM, the IR field's link to union interests and its lack of new theory led to a state of benign neglect, with the exception of some work on high performance work systems (HPWS) which found its way 
into mainstream HRM (Kaufman 2014:211). As IR faded as a field, a new field, personnel economics (PE) developed primarily in its stead, drawing from neoclassical microeconomic theory and the application of standard microeconomic concepts such as rationality, constrained maximisation, competition, incentives and equilibrium), together with other fields such as organisational economics (OE) and new institutional economics (NIE); all with a focus on firms and their management (Kaufman 2014:211). Arguably, the growing differential between returns to knowledge versus capital drove these changes in the academic fields, which were simply responding to the demands of their constituents. However, what seems to have conflated HRM theory and policy is the fact that the primary and secondary sector (and their types of work and job characteristics) have not disappeared, but simply increasingly account for less of the growth in wealth creation, as knowledge-related returns to firms continue to increase dramatically. Similarly, jobs and work in organisations can also be differentiated by the characteristics they share with capital-oriented versus knowledge-oriented work.

PE and HRM claimed coverage across all aspects of the personnel relationship, and PE also offered economic tools in support of the quest for evidence of the relationships between strategy, contingencies, fit and performance, but the difference between PE and HRM persisted in the theoretical and mathematical nature of PE's home discipline, economics, which entails trade-offs in terms of a focus on organisational culture and the complexity of multiple goals, which was better dealt with by HRM, with its home disciplines of psychology and OB (Kaufman 2014:204). Given the inseparability of valuable knowledge endowments from the individual (Polanyi 1973:9), the increasing importance of psychology and OB to the rise of knowledge work can be clearly understood. Similarly, given the intangibility of knowledge resources and the explicit measurement of their contribution to competitive advantage, the use of mathematical frameworks was perhaps more difficult than in primary and secondary sector contexts.

The mathematical frame of economics has been criticised by HRM writers as having unrealistic assumptions and concepts, particularly when abstracting and modelling aspects of people and organisations. PE's lens of rationality and competitive market efficiency clashes with the OB notion that '... employer-employee behaviour is embedded in a social context, thinking is customary and sometimes ill-logical, social comparisons and imitation are prevalent, work performance is discretionary, social relations matter, and organisations sub-optimize' (Kaufman 2014:213).

From '... the 1970s onward the fortunes of PM's improvedsurprisingly so by century's end, while those of industrial relations followed the opposite course' (Kaufman 2014:207). This is perhaps less surprising, considering the efficiency enhancements associated with the information, or knowledge, revolution, which provided technological advances which dramatically reduced the transactions costs of business.
IR, increasingly associated with unions, morphed into employment relations (ER), but with a take-up that was 'halting and lukewarm' and PM '... successfully came up with a new label that helped give the field an updated, broader and more progressive image', namely HRM (Kaufman 2014:207). At this point, the knowledge economy was on the verge of an explosion of knowledge productivity enhancement as the information revolution delivered products such as the personal computer.

\section{The era of human resource management}

In 1990 the American Society for Personnel Administration (ASPA) became the SHRM, and as from the 1980s onwards PM began to differentiate, led by academics at Harvard and Michigan Business Schools, around a focus on an emergent commitment model of managing people. The 'new HRM' promised a focus on competitive advantage through unity of interest and cost reduction through the reduction in hierarchies and control mechanisms and the development of learning organisations, enabled by employees as human capital (Kaufman 2014:208). The new power relationships associated with knowledge work no longer required supervision in the same way as capital-centric work. The divergence of the primary sector and secondary sector characteristics of work from knowledge work accelerated over this period.

Over this period (from 1980 onwards) an academic focus on high involvement was spurred on by the successes of Japanese management systems, and expanded further to include socio-technical systems and HPWS (Kaufman 2014:208). Awareness of the field's vulnerability to measurement issues (Ulrich 1997:303), and of the lack of data to benchmark progress, became particularly acute (Ulrich \& Brockbank 1989:311).

By the 1980s, the realisation had dawned that hiring the 'right' people, training them, and rewarding them well could contribute to competitive advantage. This entailed a reconceptualisation of employees from the cost side of the business equation to the asset side, or as resources, hence the increased preference for the term 'human resources' and the change in the title of personnel managers to 'Human Resource (HR) Managers' (DeNisi et al. 2014:220). This can be taken to reflect a 'tipping point' in the development of HRM, as personal computers and other technological advances shifted the nature of work toward the 'empowered' and increasingly productivity-enabled knowledge worker, and, hence, to increasing returns to knowledge that could be captured by firms.

The HRM field '... appeared to make an impressive forward lead in the 1980s and 1990s at both the practitioner and academic levels' because of a host of different reasons, including the expansion of employment law, which required HR departments to ensure compliance, as well as the contribution of $\mathrm{OB}$ and its closely allied off-shoot, organisational development (OD), as sub-fields (Kaufman 2014:209). Over this 
period, the HRM function began to expand its focus '... beyond its traditional operational and transactional role' (Conner \& Ulrich 1996:38).

These changes in the 1990s heralded a seminal differentiation in HRM literature relating to hard versus soft versions of HRM models, derived from opposing perspectives of human nature and management control strategies, corresponding to 'hard' theory $\mathrm{X}$ economic models of individuals and individual work versus 'soft' theory $\mathrm{Y}$ models premised on control through commitment. Evidence, however, at the time suggested softer models to be largely associated with corporate rhetoric and harder models more realistically to reflect employee experiences (Gratton et al. 1999:1; Truss et al. 1997:53). At this time, authors such as Conner and Ulrich (1996) also developed arguments stressing HRM's focus on the creation of value rather than corporate rhetoric.

This change in focus (from 'hard' economic models of individual work to 'soft' commitment centred work) is commensurate with the notion that individual and heterogeneous knowledge endowments provided competitive advantages denied to the homogeneity of capital. This change also had its roots in the genesis and development of $\mathrm{OB}$ which originally emerged in the 1960s from a synthesis of theory from industrial-organisational psychology, industrial sociology, human relations, organisation theory and management, and in 1971 an OB division was established by the Academy of Management in the USA. The primary interest of this new field could broadly be considered to focus on behaviour and people within the organisational context as well as the behaviour and nature of organisations within their contextual environments (Kaufman 2014).

Micro OB provided a strong focus on theory development, which could support practice and this was a de facto shift from a descriptive paradigm in HRM to a theoretical one; the vanguard of this field included behavioural scientists such as Herzberg, McGregor, Porter, Maslow and Argyris (Kaufman 2014:209). A central tenet of these writings was the notion that the social and relational dimensions of employment as well as psycho-social needs and internal motives are fundamentally related to higher productivity and performance. From this the high performance model of HRM practices, or HPWS developed, and HRM became '... at many universities a course in "applied OB"'. (Kaufman 2014:210). Given the importance of the human resource as the dominant form of competitive advantage, the legitimacy of HRM as a dominant organisational function contributing to performance can no longer be in doubt.

However, according to Marchinton (2015:176), HRM as a field has sought legitimacy through taking recourse to strategic objectives and in doing so HRM '... is likely to wither both in academic and practitioner circles'. According to the literature, over time HRM developed from a core focus on welfare and PM's, ER and legal regulation, toward a current focus on SHRM, which, some have argued, might be problematic on account of its managerial aspects, such as considering employees as 'resources' whilst neglecting the employee perspective, its thinly veiled discourse of quality enhancement that hides a work intensification agenda, and its cost reduction form, which has been perceived as hostile to workers and trade unions, and the use of fear to attain compliance (Marchinton 2015:176). Notions of managerial goals, work intensification and cost reduction, however, seem to reflect a capital-centric ideology, well suited to primary and secondary sector analysis but perhaps less so to knowledge work. Undoubtedly, unfairness and exploitation are not expected to disappear in working conditions, but to have these notions expropriated by inappropriate ideology does little to reduce the confounds or entanglements present in contemporary HRM theory and practice. Instead, it would perhaps be more helpful to look also to the new source of inequality in working contexts, and the 'new' class divide, between knowledge workers and non-knowledge workers. If theory were to be more exacting in its focus, knowledge of the 'new' inequality will better equip us to deal with it, both in relation to HRM and in broader societal terms.

Marchinton's (2015:177) critique essentially suggests that within the context of a 'race to the bottom' in terms of pay and conditions justified by a 'survival' rationale, HRM, by becoming SHRM, is losing its distinctiveness, especially in terms of its values contribution, or commitment to values, without which HRM might '... lose focus and influence, and ultimately be subsumed by other management functions, such as marketing and finance, that are better at giving businesses what they say they want.' Marchinton (2015:176) acknowledges, however, that this literature derives from the UK stream and not the US. Such critiques need to be voiced, and addressed. The UK stream seems to draw historically from the European social science literature that emerged from the theoretical and practical tensions related to the industrial revolution. In contexts of increasing returns to knowledge, and the rise in power of the knowledge worker the increased focus of HRM on SHRM seems to herald the increasing role of $\mathrm{HRM}$ as an important contributor to organisational performance. It is argued here that for the field to develop to its full potential, the primary goal of HRM should be made explicit: to maximise the returns to knowledge that can only be attained through the development of deep knowledge around human beings as human resources. This explains the rise of sub-fields such as talent management and human capital within HRM, but until this primary goal is made explicit, the tensions highlighted by Marchinton (2015:176) and others will continue to manifest, as may criticisms of subordinate fields like talent management as 'fads' in managerial or HR discourse.

Indeed, the notion that HRM has become SHRM is widespread, as HR has become a strategic partner in organisations (Gratton \& Truss 2003:74) because of increasing recognition that '... human resources are critical to the functioning of organisations in the service and knowledge 
economies' (Stone \& Deadrick 2014:195). This is surely a positive development. The trajectory of HRM as a field has been inextricably shaped by the increasing power of knowledge workers, and the need to foster trust as, 'American organisations began to stress non-unionised HRM practices', together with Japanese management principles based on the nation of employees as critical resources that underpin competitive advantage, which resulted in a shift '... from a "personnel" function to a human relations, then labour relations, then industrial relations, and most recently strategic HRM function' (Stone \& Deadrick 2014:195).

SHRM has been defined as '... ideas intended to increase the responsiveness of the human resource function to organisational goals', a literature-defined definition (Mesch, Perry \& Wise 1995:385). SHRM '... is about the relationship between human resource management...and strategic management in an organisation', and '... covers broad organisational concerns related to structure, culture, management of change, organisational effectiveness, performance, competence, matching resources to future business requirements and employee development (Nigam et al. 2011:148). However, all these dimensions can be conceptualised as representing dimensions of the knowledge equation; how HRM relates to performance through the way knowledge is leveraged. SHRM offers the central rationale for what this knowledge is leveraged toward, or what specific outcomes are valued more than others.

\section{Persistent lack of paradigmatic differentiation}

On the basis of their research, Boudreau and Lawler (2014) stress that despite:

... compelling arguments supporting human resources management as a key strategic issue in most organisations, our research and that of others have found that human resource executives often are not involved in key strategic decisions and remain stubbornly traditional. (p. 232)

Organisations seem to not be changing their human capital management policies, practices and processes, or redesigning their HR functions. Further, according to Boudreau and Lawler (2014), missing:

... almost entirely from the list of HR focuses are such key organisational challenges as improving productivity, increasing quality, facilitating mergers and acquisitions, managing knowledge, implementing change, developing business strategies, and improving the ability of the organisation to execute strategies. (p. 233)

This is a symptom of what they term 'stubborn traditionalism' in HR. This 'stubborn traditionalism' is taken here to represent the conflation of capital-centric theory and practices with knowledge-centric theory and practices, the confounding of which continues to hold back the field; and the lack of a realisation that knowledge work is sharply differentiated from non-knowledge work by its increasing heterogeneity and complexity. This is considered a persistent lack of paradigmatic differentiation.
Figure 1 illustrates the different paradigms and changes in the forms of work that have shaped the field of HRM. It is argued in this article that the primary contribution of HRM to firm performance is in the way it fosters deep knowledge of a firm's human resources and uses this knowledge in turn to leverage valuable knowledge endowments. Exponential returns to knowledge might be captured and sustained by effective HRM, as the efficiency paradigm of capital-centric work is supplanted by the effectiveness paradigm of knowledge-centric work. The current state of HRM theory and practice, and its condition of 'stubborn traditionalism' (Boudreau \& Lawler 2014:233) is taken to reflect a lack of differentiation between paradigmatic theory and practice which is alternatively better suited to either of two entirely different forms of work, with knowledge work at the extreme of a continuum on which low-knowledge work is at the other extreme. This relationship is illustrated in Figure 2.

Figure 2 illustrates the differences in work that reflect what is argued to be a fundamental dichotomy in HRM theory and practice, with knowledge work differentiated from non-knowledge work primary as a result of the difference between perfectly competitive conditions of work experienced by homogenous labour versus the more monopolistic characteristics of knowledge work which endow knowledge workers with relatively more power in labour markets.

\begin{tabular}{|c|c|c|}
\hline $\begin{array}{l}\text { Pre-capitalistic } \\
\text { paradigm }\end{array}$ & $\begin{array}{l}\text { Capitalistic paradigm } \\
\text { 'Capitalism' Industrial } \\
\text { relations versus } \\
\text { personnel Management }\end{array}$ & $\begin{array}{l}\text { Post-capitalistic } \\
\text { paradigm 'Knowledgism' } \\
\text { Genesis of HRM } \\
\text { discipline }\end{array}$ \\
\hline $\begin{array}{l}\text { Industri } \\
\text { revoluti }\end{array}$ & \multicolumn{2}{|c|}{$\begin{array}{l}\text { Information } \\
\text { revolution }\end{array}$} \\
\hline \multirow[t]{2}{*}{$\begin{array}{l}\text { Power relationships } \\
\text { related to primary } \\
\text { sector characteristics }\end{array}$} & $\begin{array}{l}\text { Power relationships } \\
\text { dominated by capital } \\
\text { and powerless } \\
\text { homogenous labour } \\
\text { Secondary sector } \\
\text { characteristics }\end{array}$ & $\begin{array}{c}\text { Power relationships } \\
\text { dominated by } \\
\text { knowledge and } \\
\text { heterogeneous labour } \\
\text { as knowledge workers } \\
\\
\text { Tertiary sector } \\
\text { characteristics }\end{array}$ \\
\hline & $\begin{array}{l}\text { Liberal arts theory } \\
\text { response to Industrial } \\
\text { Revolution Economics/ } \\
\text { Sociology/Aggregated level } \\
\text { of analysis effective in } \\
\text { description and } \\
\text { explanation }\end{array}$ & $\begin{array}{c}\text { Psychology/OB } \\
\text { individual level of } \\
\text { analysis-heterogeneity } \\
\text { of motivation } \\
\text { commitment and } \\
\text { performance }\end{array}$ \\
\hline
\end{tabular}

FIGURE 1: Human resource management and its emergence as a post-capitalistic phenomenon.

\begin{tabular}{c} 
Non-knowledge work. \\
Perfectly competitive. \\
$\begin{array}{c}\text { Lack of differentiation. } \\
\text { Powerless in relation } \\
\text { to capital }\end{array}$ \\
\hline Low labour power
\end{tabular}

FIGURE 2: The knowledge work/non-knowledge work continuum. 
The central thesis of this article is, therefore, that HRM as a field needs to develop deeper knowledge of its individual human resources in order to offer to firms what other functions cannot, namely the ability to maximise the returns to knowledge that are fundamentally inseparable from the individuals that possess it. Given the potential for exponential returns to knowledge available in globalised competitive contexts, the role of HRM is predicted to increase in its functional importance over time, making HR an indispensable partner in the quest for organisational performance.

\section{Conclusion}

The objective of this article was to present an argument that the paradigm of capital-centric theory and practice in HRM describes and predicts relationships appropriate to industrialtype work, or work in which capital dominates in its power relationships with labour. This paradigm is to some extent incommensurate with the paradigm of knowledge-centric theory and practice in HRM, which describes and predicts relationships appropriate to knowledge work, or work in which knowledge workers possess scarce (largely) tacit knowledge and thereby have more power in relation to capital than workers in the capital-centric paradigm. In making this argument, it was acknowledged that inequality between the performances of firms (as well as individuals, industries and economies) might be set to dramatically increase, as potentially exponential returns to knowledge are captured by some and not others. In the same way as knowledge might now be the primary driver of inequality, it was argued that HRM strategy that focused on the maximisation of returns to knowledge should be the primary rationale for HRM's contribution to competitive advantage, as the HR function is perhaps the most suited to managing the increasing value of individual knowledge workers and their heterogeneous knowledge assets.

\section{Acknowledgements Competing interests}

The author declares that he has no financial or personal relationship(s) that may have inappropriately influenced him in writing this article.

\section{References}

Boudreau, J. \& Lawler, E.E., 2014, 'Stubborn traditionalism in HRM: Causes and consequences', Human Resource Management Review 24, 232-244.

Callaghan, C.W., 2012, 'Capitalism is dead: Long live knowledgism', International Corporate Governance Conference, Johannesburg, 22-23 October.

Conner, J. \& Ulrich, D., 1996, 'Human resource roles: Creating value, not rhetoric', Human Resource Planning 19(3), 38-49.

DeNisi, A.S., Wilson, M.S. \& Biteman, J., 2014, 'Research and practice in HRM A historical perspective', Human Resource Management Review 24, 219-231.

Gordon, R.A. \& Howell, J.E., 1959, Higher education for business, Columbia University Press, New York.

Gratton, L., Hope-Hailey, V., Stiles, P. \& Truss, C., 1999, Corporate rhetoric and human reality, Oxford University Press, Oxford.

Gratton, L. \& Truss, C., 2003, 'The three-dimensional people strategy: Putting human resources policies into action', Academy of Management Executive 17(3), 74-86.

Jackson, S.E., Schuler, R.S. \& Jiang, K., 2014, 'An aspirational framework for strategic human resource management', The Academy of Management Annals 8(1), 1-56.

Kaufman, B.E., 2014, 'The historical development of American HRM broadly viewed', Human Resource Management Review 24, 196-218.

Marchinton, M., 2015, 'Human resource management (HRM): Too busy looking up to see what is going longer term', Human Resource Management Review 25, 176-187.

Mesch, D.J., Perry, J.L. \& Wise, L.R., 1995, 'Bureaucratic and strategic human resource management: An empirical comparison in the Federal Government', Journal of Public Administration Research and Theory: J-PART 5(4), 385-402.

Mincer, J., 1958, 'Investment in human capital and personal income distribution', The Journal of Political Economy 66(4), 281-302.

Nigam, A.K., Nongmaithem, S., Sharma, S. \& Tripathi, N., 2011, 'The impact of strategic human resource management on the performance of firms in India', Journal of Indian Business Research 3(3), 148-167.

Nonaka, I., 1994, 'A dynamic theory of organizational knowledge creation', Organization Science 5(1), 14-37.

Organisation of Economic Co-operation and Development (OECD), 1996, The knowledge-based economy, viewed 24 May 2015, from http://www.oecd.org/sti/ sci-tech/1913021.pdf

Pierson, F.C., 1959, The education of American businessmen: A study of universitycollege programs in business administration, McGraw-Hill, New York.

Piketty, T., 2014, Capital in the twenty-first century, Belknap, Cambridge, MA.

Polanyi, M., 1973, Personal knowledge: Toward a post-critical philosophy, Routledge \& Kegan Paul, London.

Stone, D., Deadrick, D.L., Lukaszweski, K.M. \& Johnson, R., 2014, 'The influence of technology on the future of human resource management', Human Resource Management Review 25, 216-231.

Stone, D.L. \& Deadrick, D.L., 2014, 'Challenges and opportunities affecting the future of human resource management', Human Resource Management Review 25, 139-145.

Truss, C., Gratton, L., Hope-Hailey, V., McGovern, P. \& Stiles, P., 1997, 'Soft and hard models of human resource management', Journal of Management Studies 34(1), 53-73.

Ulrich, D., 1997, 'Measuring human resources: An overview of practice and a prescription for results', Human Resource Management 36(3), 303-320.

Ulrich, D. \& Brockbank, W., 1989, 'Beyond belief: A benchmark for human resources', Human Resource Management 28(3), 311-335.

Von Hippel, E., 1994, 'Sticky information' and the locus of problem solving: Implications for innovation', Management Science 40(4), 429-439.

Wright, P.M. \& Haggerty, J.J., 2005, 'Missing variables in theories of strategic human resource management: Time, cause, and individuals', Management Revue 16(2), 164-173. 